\title{
Las máquinas de Leonardo da Vinci
}

María Cecilia Tomasini ${ }^{\bullet}$

\section{Resumen}

Leonardo da Vinci fue un inquieto observador de la naturaleza y se empeñó en descifrar su leyes. Su intuición científica y su curiosidad lo llevaron a explorar la cinemática, la mecánica, la hidrodinámica y la óptica entre otras áreas de la física. Si bien no desarrolló teorías matemáticas ni experiencias que apoyaran sus investigaciones, su visión objetiva y analítica de la naturaleza lo sitúan como un pionero del pensamiento científico moderno.

Palabras clave: Leonardo, Renacimiento, máquinas, ciencia moderna.

\begin{abstract}
Leonardo da Vinci was a restless observer of nature and set out to decipher its laws. His scientific intuition and curiosity led him to explore the kinematics, mechanics, hydrodynamics and optics and other areas of physics. While not developed mathematical theories and experiences to support their research, analytical and objective view of nature place him as a pioneer of modern scientific thought.
\end{abstract}

Keywords: Leonardo, Renaissance, machines, modern science. 
Uno de los aspectos más fascinantes de la obra de Leonardo da Vinci (14521519) es su interés en el diseño de máquinas y en el estudio de diversos fenómenos físicos. Al observar sus bocetos nadie puede evitar sentirse doblemente subyugado, tanto por la indiscutible belleza de sus dibujos hechos con delicados y precisos trazos de sanguina y carbonilla, como por la minuciosa y detallada descripción de los mecanismos y de las herramientas empleados en sus proyectos. En los esbozos de Leonardo, hasta los engranajes son bellos. Pero, más allá de la belleza, estos diseños dan muestra del incesante afán del artista por conocer la naturaleza y sus secretos, y de su inagotable genio como inventor.

El historiador de la ciencia A. C. Crombie considera a Leonardo como uno de los físicos- ingenieros más importantes de su época. Según este autor, Leonardo basó sus investigaciones, directa o indirectamente, en los estudios de física matemática realizados previamente, hacia fines de la Edad Media, en Oxford y en París. ${ }^{1}$ Se ocupó, sobre todo, de problemas concernientes a la mecánica y a la hidráulica, realizando incluso varios progresos en cuanto al conocimiento de estos temas. ${ }^{2}$ En opinión de Crombie, aún cuando los estudios de Leonardo nunca fueron publicados, podrían haber influido en el desarrollo posterior de la ciencia: “...A Aunque (Leonardo) no escribió ningún libro, y sus ilegibles notas escritas en espejo cubiertas con bosquejos no fueron descifradas y publicadas hasta mucho más tarde... su obra no se perdió para la posteridad inmediata. Sus manuscritos fueron copiados en el siglo XVI y sus ideas mecánicas robadas por Jerónimo Cardano... y puede que pasaran a Stevin y, a través de Bernardino Baldi, a Galileo, Roberval y Descartes...".

Sin embargo, no todos los historiadores de la ciencia comparten este punto de vista. Por ejemplo George Sarton, quien ha analizado exhaustivamente la obra de Leonardo, sostiene que el artista renacentista no fue ni un auténtico inventor ni un

1. Cf. A. C. Crombie, Historia de la Ciencia: De San Agustín a Galileo; Tomo 2, Siglos XIIIXVII; p. 92. Sobre los avances de la ciencia física medieval véase este mismo autor, Op. cit., p. 86 y ss.; también E. Grant, La ciencia física en la Edad Media; y D. C. Lindberg, Los inicios de la ciencia occidental.

2. Cf. A. C. Crombie, Op. cit., p. 117 y ss.

3. Ibid. Jerónimo Cardano (1501- 1576), matemático y filósofo italiano a quien se debe la resolución de la ecuación de tercer grado. Simon Stevin (1548- 1620), físico, matemático e ingeniero flamenco, uno de los pioneros en la formulación matemática y empírica de la ciencia. Bernardino Baldi (1563- 1617), físico, matemático y literato italiano, traductor de numerosas obras. Galileo Galilei (1564- 1642), matemático, físico y astrónomo italiano, considerado como uno de los fundadores de la ciencia moderna. René Descartes (1596-1650), filósofo, matemático y físico francés, fundador del método racionalista (cartesianismo) y uno de los fundadores de la geometría analítica. Gilles Personne de Roberval (1602- 1675), matemático francés precursor del cálculo infinitesimal e inventor de un sistema de balanzas. 
auténtico científico ya que “...un científico debe probar, o por lo menos explicar claramente, qué es lo que piensa...". ${ }^{4}$ Sarton puntualiza tres rasgos de Leonardo que impiden valorar objetivamente su talento científico: en primer lugar, no siempre es posible saber cuál es el significado de sus escritos puesto que sus conceptos no son muy claros y a menudo se contradice; en segundo lugar, casi todas sus ideas tienen un origen medieval, por lo tanto no son auténticas innovaciones ni aportes originales al desarrollo de la ciencia y de la tecnología; y en tercer lugar, sus fuentes provienen fundamentalmente de la tradición oral y no de la literatura académica derivada de las universidades. Agrega este autor que "...por instinto (Leonardo) fue mecánico y trató de comprender los fenómenos de la mecánica y de la dinámica; hasta trató de comprender las reglas de la hidráulica y de la aerodinámica, pero en vano....". En cuanto al invento, Sarton sostiene que se requieren tres fases: la pura idea, la experimentación o implementación (ensayos, puesta a punto de los aparatos, etc.), y la aplicación práctica que demuestre que sirve para algo útil. En vida de Leonardo, muchos de sus "inventos" nunca salieron del papel. Por esta razón G. Sarton duda en calificar a Leonardo como científico e inventor.

Es indudable que G. Sarton juzga y analiza la obra de Leonardo desde el punto de vista de la ciencia moderna: una ciencia no sólo basada en la observación del fenómeno natural, sino apoyada y corroborada por medio de la experimentación y la formulación matemática. Sin embargo, esta ciencia surge recién a mediados del siglo XVI -posteriormente a la muerte del Leonardo- madurando lenta y arduamente a lo largo de los siglos subsiguientes. ${ }^{6}$ En mi humilde opinión, no creo que pueda valorarse cabalmente la labor científica e ingenieril de Leonardo a menos que se lo considere inserto en un contexto cultural de transición entre el pensamiento "especulativo y espiritual" del Medioevo y el pensamiento "materialista y racional" que dominará los siglos posteriores. Por otra parte, si bien muchos de los diseños de Leonardo no llegaron a implementarse en vida del artista, se ha comprobado desde hace tiempo que la mayoría de sus máquinas funcionan a la perfección. ${ }^{7}$

4. G. Sarton, Leonardo da Vinci, arte y ciencia. En Seis alas: hombres de ciencia renacentistas, p. 215.

5. Ibid., p. 219.

6. En general se considera que la Ciencia Moderna surge con Nicolás Copérnico (1473-1543) y, más exactamente, con la publicación de su obra De Revolutionibus Orbium Coelestium en el año 1543.

7. Por ejemplo, en el año 1939, en el Palazzo della Triennale, se expusieron en funcionamiento gran cantidad de maquinarias construidas según los dibujos de Leonardo. Cf. A. Marinoni y M. Meneguzzo, Las Maquinarias; en Leonardo da Vinci. Dibujos. La invención y el arte en el lenguaje de las imágenes, p. 183. 
De todas las máquinas imaginadas por Leonardo, sus artefactos voladores son los que han despertado mayor admiración. El sabio renacentista confiaba en poder encontrar el secreto del vuelo estudiando el ala de las aves. La mayor parte de sus esquemas muestran máquinas piloteadas por hombres, con alas articuladas similares a las de los pájaros. Como es sabido, dedicó gran cantidad de bocetos a este tipo de análisis (véase la figura 1). Hoy en día sabemos que el secreto de la sustentación aerodinámica no reside en las articulaciones de las alas, sino en su perfil. Nuestros modernos aviones se sostienen en el aire en virtud de la diferencia de presión entre la parte superior e inferior del aparato. Esta diferencia de presión se genera gracias al perfil de las alas y del fuselaje, siempre que la velocidad del avión respecto del aire sea suficientemente alta. ${ }^{8}$ Estos principios, que constituyen en fundamento del vuelo, se desconocían en los siglos XV y XVI.

Leonardo no sólo investigó el vuelo horizontal, sino que diseñó una máquina que es "universalmente reconocida como la primera y genial anticipación del vuelo vertical ". "Se trata del denominado "tornillo aéreo" (véase la figura 2), antepasado de los modernos helicópteros. Este proyecto consiste en una superficie en forma helicoidal, arrollada en torno de un eje vertical. Tal como las alas articuladas de Leonardo, su tornillo aéreo no puede elevarse por sí mismo ni sustentarse en el aire, puesto que fue diseñado ignorando el perfil necesario para producir la diferencia de presión que lo sostendría en vuelo. Por otra parte, ninguna de sus máquinas voladoras podría alcanzar la velocidad necesaria para elevarse ya que los "motores" de los que se disponía en el Renacimiento tenían muy baja potencia. ${ }^{10}$

8. En la sustentación aerodinámica influyen también otros factores como la superficie del ala, el ángulo de ataque, etc. Véase M. Alonso y E. J. Finn, Física; cap. 14.10, Movimiento de fluidos.

9. A. Marinoni y M. Meneguzzo, Op. cit., p. 230.

10. En la mayoría de los diseños de Leonardo la fuera motriz es proporcionada por el trabajo humano. Esta fuente de energía es demasiado pequeña como para suministrar la diferencia de velocidad entre el aparato y el aire necesaria para la elevación. 


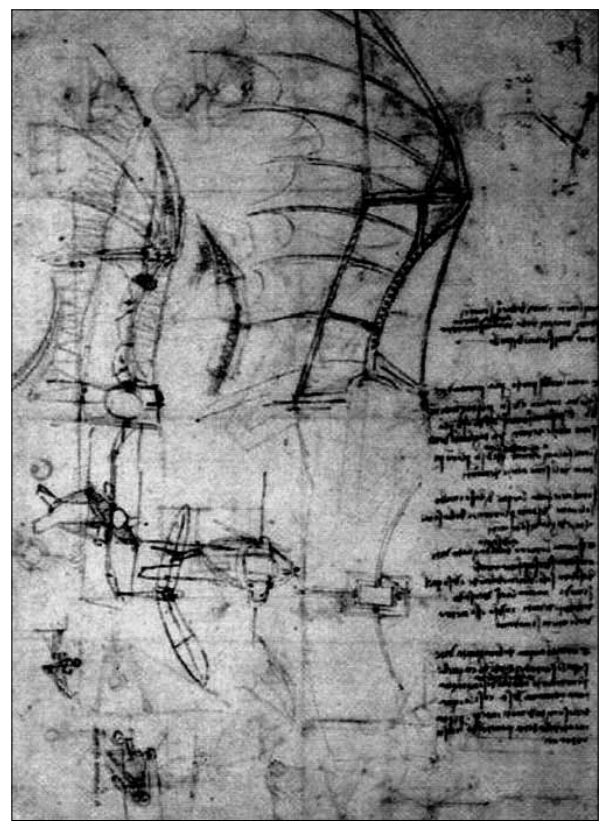

Figura 1: estudio de máquina voladora. ${ }^{11}$

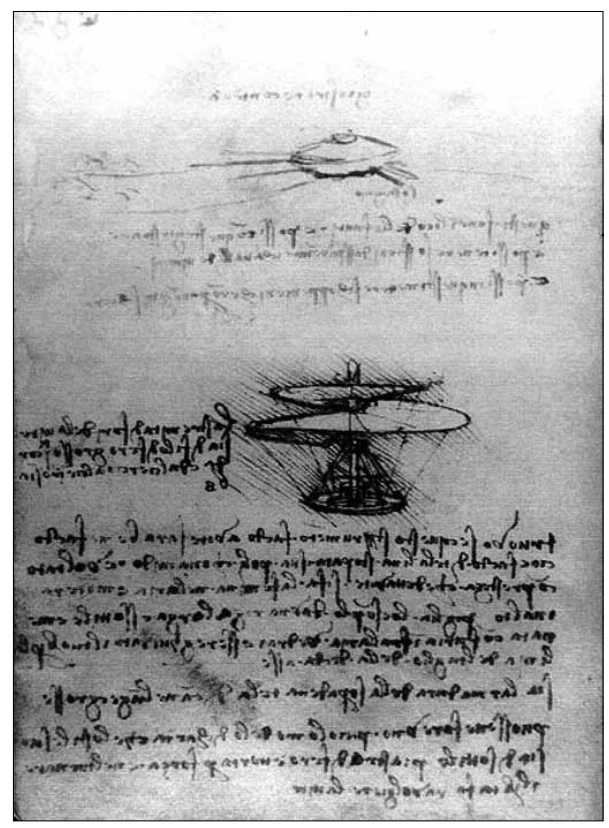

Figura 2 : tornillo aéreo. ${ }^{12}$

Si bien Leonardo no logró descifrar los secretos del vuelo, llegó a diseñar un paracaídas que efectivamente permitiría a un hombre arrojarse sin peligro desde cualquier altura. Este invento consistía en un enorme aparato de forma piramidal, que disminuía la velocidad de la caída gracias a la resistencia opuesta por su enorme superficie. ${ }^{13}$

Como ya hemos dicho, los fundamentos de la sustentación aerodinámica - esto es, el perfil del ala, la velocidad relativa entre el aparato y el aire, y otros elementos como el ángulo de ataque, etc.- eran desconocidos en el Renacimiento. Sin embargo, Leonardo exploró los misterios del vuelo agotando todos los recursos de su tiempo. En este sentido, hasta el historiador G. Sarton sostiene que Leonardo "....hizo todo lo que era posible hacer en su tiempo.... (y)...merece completamente ser considerado como uno de los pioneros de la aviación". ${ }^{14}$

11. Codex Atlanticus, folio 846 v. Imagen extraída de Wikimedia Commons.

12. Codex $B$, folio 83 v. Imagen extraída de Wikimedia Commons.

13. Cf. Ibid., p. 229

14. G. Sarton, Op. cit., p. 219. 
Entre los grandes intereses de Leonardo figuran también las máquinas de guerra. En una época en la que los estados italianos sostenían permanentes conflictos entre sí, Leonardo dirigió una carta a Ludovico el Moro presentándose a sí mismo, ante todo, como ingeniero militar. En esta carta el sabio describe algunas de sus armas: “....Tengo todavía maneras de bombardas comodísimas y fáciles de llevar, y con ellas lanzar diminutos guijarros a semejanza de las tempestades... (...) ...Y si ocurriese estar en la mar, tengo maneras de muchos instrumentos sumamente aptos para atacar y defender navios... (...) ...haré carros cubiertos, seguros y no atacables... (...) ...Alli donde faltase la operación de las bombardas, compondré catapultas, balistas, trabucos y otros instrumentos de admirable eficacia, y fuera de lo conocido...". ${ }^{15}$

Leonardo imaginó bombardas -o cañones-accionadas por la fuerza del vapor, en un momento en el que las máquinas de vapor aún no eran soñadas por ningún inventor. ${ }^{16}$ Uno de sus dibujos ilustra la manera de saturar con disparos el frente de guerra (véase la figura 3). En este diagrama es posible apreciar el interés de Leonardo en comprender el tiro oblicuo. Sus dibujos revelan una aproximación intuitiva al problema: se basan en la simple observación, y no en el estudio analítico del movimiento, ya que no son tenidos en cuenta ni la velocidad del disparo ni el ángulo de tiro, elementos que determinan la forma de la parábola, su altura y su alcance. Sin embargo las observaciones de Leonardo se consideran hoy en día muy aceptables, dado que en su tiempo aún no se había formulado una teoría cinemática adecuada. ${ }^{17}$

También diseñó gigantescas catapultas realizadas con maderas tensadas y curvadas que almacenan elásticamente la fuerza liberándola de golpe. En la figura 4, la tabla de madera es arqueada por medio de una cuerda sujeta a una rueda dentada. Probablemente la rueda dentada, al trabarse, serviría para sostener la cuerda en su lugar impidiendo que la catapulta se disparase antes de tiempo. El disparo parece accionarse por medio de un martillo que destraba la cuerda. El mecanismo es simple, y recurre al mismo principio que permite almacenar energía en los resortes.

15. Carta de Leonardo a Ludovico el Moro, 1482. Cf. A. Marinoni y M. Meneguzzo, Op. cit., p. 232. Posiblemente la palabra que en la edición citada se ha traducido como "manera" podría entenderse como "proyecto" o "diseño". Nota del autor.

16. Cf. Ibid., p. 234. Como es sabido, la máquina de vapor fue inventada por el inglés James Watt (1736-1819) recién en el siglo XVIII. Su implementación a gran escala dio origen a la llamada Revolución Industrial.

17. Cf. Ibid., p. 153. 


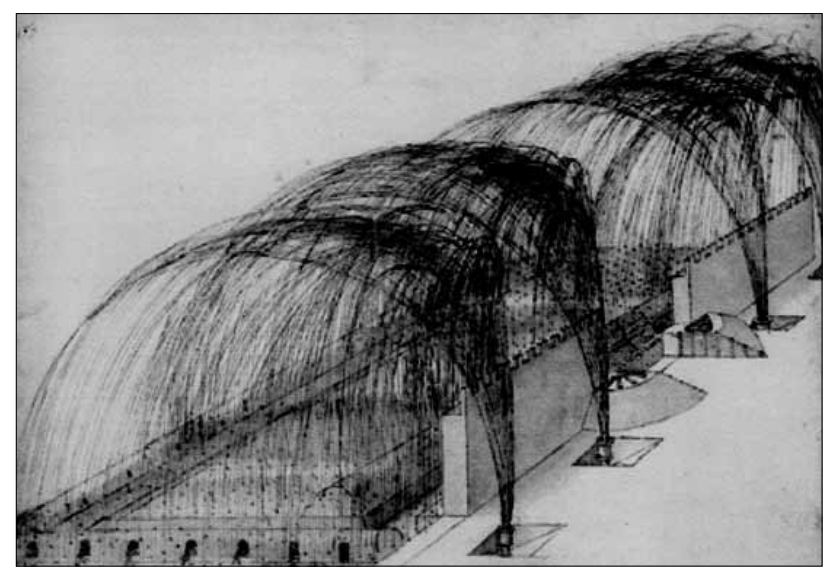

Figura 3: disparos de artillería en el frente de guerra. ${ }^{18}$

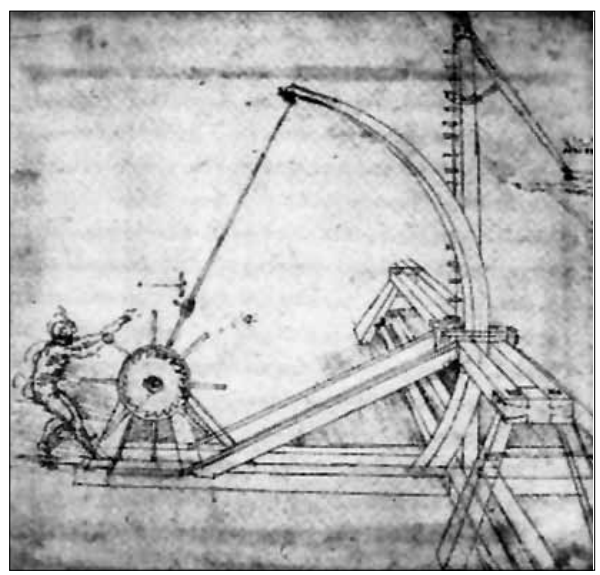

Figura 4: catapulta. ${ }^{19}$

Leonardo se interesó por casi todos los problemas mecánicos y cinemáticos de su época, como la caída libre de los cuerpos, el funcionamiento de las palancas y de las poleas, y la trasmisión de esfuerzos por medio de engranajes y otros sistemas. Dice Crombie: “...(Leonardo) reconoció que el brazo (efectivo) de una balanza era la línea que, pasando por el fulcro ${ }^{20}$, formaba ángulos rectos con la perpendicular que pasaba por los pesos suspendidos... (...) ...Reconoció que la velocidad de una bola que caía por un plano inclinado era uniformemente acelerada y mostró que

18. Codex Atlanticus, folio 72 r, fragmento. Extraído de Imágenes Google.

19. Codex Atlanticus, folio 141 r, fragmento. Extraído de Imágenes Google.

20. Punto de apoyo, gozne o bisagra. 
la velocidad de un cuerpo que cae aumentaba en la misma cantidad para una caída vertical dada, tanto si descendía vertical como oblicuamente. Reconoció también... (...) ...que el principio del trabajo era incompatible con el movimiento perpetuo... (...) ...utilizó el principio del trabajo, con el de la palanca, para desarrollar su teoría de las poleas y otras aplicaciones mecánicas. En hidrostática reconoció el principio fundamental de que los líquidos trasmiten presión... (...) ...en hidrodinámica desarrolló el principio de que... cuanto menor es la sección [que atraviesa un dado caudal] mayor es la velocidad del flujo de líquido... (...) ...Además de sus estudios sobre Mecánica, Leonardo utilizo también la geometría griega en un intento por mejorar la teoría de las lentes y del ojo...". ${ }^{21}$ También en el campo de la óptica el sabio renacentista nos ha legado un buen número de estudios tanto teóricos como prácticos. Por ejemplo, uno de sus bocetos nos muestra una máquina para tallar lentes usando cristales de gran tamaño (véase la figura 5). El sistema consiste en una gigantesca rueda vertical colocada sobre el cristal a biselar, que se sitúa horizontalmente. La rueda es accionada por medio de una manivela ubicada a la derecha del dibujo. Mientras el vidrio gira en un plano horizontal, la rueda lo hace verticalmente, ahuecando su interior. Este doble movimiento es sincronizado por un sistema de engranajes, que se muestran a la izquierda de la figura.

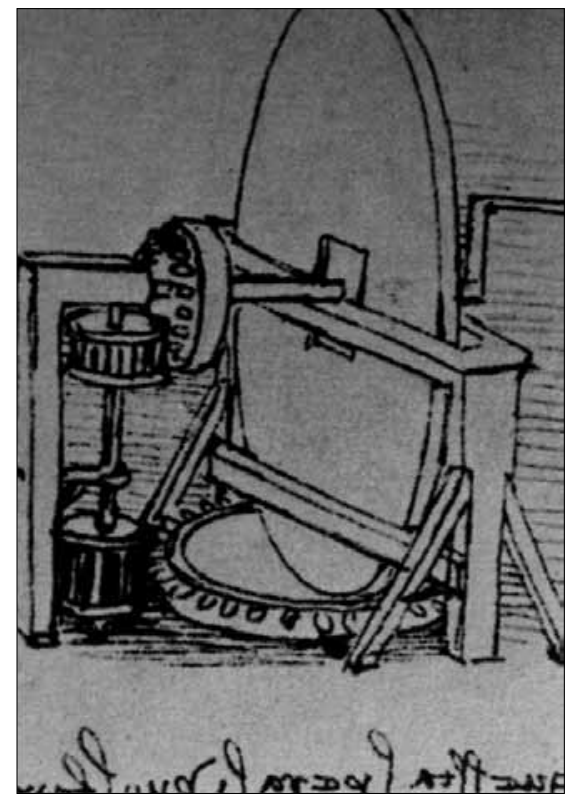

Figura 5: máquina para tallar lentes. ${ }^{22}$

21. Cf. A. C. Crombie, Op. cit., p. 117 y ss.

22. Codex Atlanticus, fragmento. Extraído de Wikimedia Commons. 
Para finalizar este fugaz recorrido a través de las maquinarias de Leonardo, me referiré brevemente a sus estudios sobre el cuerpo humano. Su interés en el funcionamiento y en la "mecánica" del cuerpo le llevaron a realizar numerosísimos estudios anatómicos. Según G. Sarton "...puede decirse que la anatomía humana fue fundada por dos hombres... Leonardo y, algo más tarde, Andrea Vesalio...". 23 Lamentablemente, sus observaciones y dibujos nunca llegaron a ser publicados. Por el contrario, Vesalio publicó sus estudios en el año 1543, bajo el título La fábrica del cuerpo humano (en latín, De humanis corporis fabrica) y por esa razón fueron sus estudios, y no los de Leonardo, los que sirvieron de punto de partida para el posterior desarrollo de la anatomía moderna.

Leonardo consideraba el cuerpo humano como un sistema mecánico. Por ejemplo, “...(defendió) la idea de que el corazón era un músculo... y (construyó) modelos para ilustrar el funcionamiento de sus válvulas... ". 24 También realizó diseños en los que sustituía los tendones por alambres, en el afán de comprender la acción de los músculos. ${ }^{25}$ En síntesis, Leonardo fue un pionero de la ciencia biomecánica, puesto que comprendió cabalmente la importancia del estudio de la mecánica aplicada al movimiento del cuerpo del hombre y de todos los seres vivientes. En sus propias palabras "La ciencia mecánica es la más noble y por sobre todas, la más útil, viendo que por medio de ella todos los cuerpos animados que tienen movimiento realizan sus acciones". ${ }^{26}$

En fin, la curiosidad y las inquietudes de Leonardo no tuvieron límite. Sus intereses lo llevaron a saltar, permanentemente, de un tema a otro, llenado sus cuadernos de bocetos y proyectos de la más amplia variedad. Así, en los Codex de Leonardo se suceden, sin solución de continuidad, estudios de facciones y expresiones, análisis de plantas y rocas, apuntes y bosquejos de sus cuadros, esquemas anatómicos y diseños de aparatos de la más diversa índole. Hoy en día sus dibujos nos siguen fascinando porque son el testimonio más claro de su inagotable e ingeniosa inventiva.

23. G. Sarton, Op. cit., p. 220. Andrea Vesalio (1514- 1564) fue un médico y anatomista flamenco, nacido en Bruselas, y universalmente reconocido como el padre de la moderna anatomía. Véase G. Sarton, Ala quinta, en Op. cit., p. 171 y ss. y A. G. Debus, El hombre y la naturaleza en el Renacimiento.

24. A. C. Crombie, Op. cit., p. 200.

25. Cf. F. Saxl, Ciencia y Arte en el Renacimiento Italiano; en La vida de las imágenes.

26. Cf. B. Le Veau, Biomecánica del movimiento humano, p. 7. 


\section{Bibliografía}

- M. Alonso y E. J. Finn, Física. Ed. Addison Wesley Longman, México, 2000.

- C. Bertelli, G. Briganti e A. Giuliano, Storia dell'Arte Italiana. Tomo III. Unitá 15. Ed. Electa, Bruno Mondadori, Milano, 1990.

- A. C. Crombie, Historia de la Ciencia: De San Agustín a Galileo. Tomo 2: Siglos XIII- XVII. Ed. Alianza, Madrid, 1996.

- A. G. Debus, El hombre y la naturaleza en el Renacimiento. F. C. E., Breviarios, 1996.

- E. Grant, La ciencia física en la Edad Media. F. C. E. 1983.

- B. Le Veau, Biomecánica del movimiento humano. Ed. Trillas, Mexico, 1991.

- D. C. Lindberg, Los inicios de la ciencia occidental. Ed. Paidós, Bs. As., 2002.

- A. Marinoni y M. Meneguzzo, Las Maquinarias; en Leonardo da Vinci. Dibujos. La invención y el arte en el lenguaje de las imágenes. Ed. Debate, Madrid, 1994.

- G. Sarton, Leonardo da Vinci: arte y ciencia. En Seis alas: hombres de ciencia renacentistas. Ed. Eudeba, 1965.

- F. Saxl, Ciencia y Arte en el Renacimiento Italiano. En La vida de las imágenes. Ed. Alianza Forma, Madrid, 1989.

- R. van Dulmen, Los inicios de la Europa Moderna. Historia Universal, Editorial Siglo XXI, Madrid, 1998. 